UDK: $811.163 .4^{*} 373.45$

DOI: $10.33669 / \mathrm{KJ} 2021-32-08$

primljeno / received: 23.9.2021.

prihvaćeno / accepted: 15. 12.2021.
Pregledni naučni rad

\section{Hatidže Burnić}

Tehnički fakultet Univerziteta u Bihaću

Alije Isakovića 5, 77000 Bihać

Bosna i Hercegovina

hatidze_b@hotmail.com

\title{
Semantička adaptacija frekventnih germanizama u oblasti domaćinstva
}

Sažetak: Zadatak analize adaptacijskih procesa je opisati kroz koje je promjene prošla strana riječ u primarnoj fazi, odnosno od trenutka posuđivanja do formiranja osnovnog oblika - koji se u kontaktnoj lingvistici naziva replika - i koje se promjene javljaju na replici u sekundarnoj fazi, odnosno od trenutka integracije u sistem jezika primatelja nadalje. U ovom radu analizira se semantička adaptacija frekventnih germanizama u bosanski jezički sistem i stavlja se fokus na konceptualno polje "domaćinstvo". Glavni cilj je utvrđivanje značenjskih promjena koje preuzete riječi iz njemačkog jezika prolaze u toku preuzimanja i prilagođavanja u bosanski jezički sistem. Prilikom analize korištena je kontaktnolingvistička metodologija Rudolfa Filipovića u kojoj se adaptacijski procesi rasčlanjuju na primarnu i sekundarnu fazu adaptacije. Komparativnom metodom uspoređena su značenja njemačkih modela sa značenjima bosanskih replika, te su promjene klasificirane na tri kategorije: nulta semantička ekstenzija, suženje značenja i proširenje značenja.

$\mathrm{Na}$ temelju analize adaptacijskih promjena u primarnoj fazi utvrđeno je da su germanizmi uglavnom preuzeti u bosanski jezik sa svojim konkretnim značenjima ali zabilježena je i kategorija suženje u značenjskom polju. Za razliku od primarne adaptacije, sekundarna adaptacija obuhvata promjene koje nastaju na formiranoj replici. Te promjene ne povezuju se više s njemačkim jezikom jer su uvijek vezane samo za bosanski jezički sistem i njegova pravila. To dokazuju primjeri germanizama kod kojih je u fazi sekundarne adaptacije došlo do proširenja značenja upotrebom metafore, metonimije, pejorizacije, pučke etimologije i elipse.

Ključne riječi: germanizmi, semantička adaptacija, primarna i sekundarna faza 


\section{Uvod}

Za potrebe analize frekventnih germanizama u bosanskom jeziku, formiran je korpus od preko hiljadu germanizama. Korpus se sastoji od sakupljenih germanizama u okviru rada Germanizmi u štampi Bosanske krajine gdje su ekscerpirani germanizmi iz najčitanijih novina na bosanskom govornom području Bosanske krajine: Dnevni avaz, Krajina, Moja Sana i Reprezent.

U ovom radu fokus će biti stavljen na analizu semantičke adaptacije germanizama iz područja domaćinstva s obzirom na to da se u pomenutom radu došlo do rezultata da su germanizmi u području domaćinstva frekventniji u odnosu na druga područja.

Teorijska podloga ovog rada je prvenstveno studija Rudolfa Filipovića Jezici u kontaktu, odnosno njegova terminologija i model jezičkog posuđivanja na koji se poziva većina germanista.

U jezičkom posuđivanju Filipović, oslanjajući se na mišljenje Uriela Weinreicha, ističe tri osnovna elementa od kojih polazi svako jezičko istraživanje: mjesto dodira, bilingvalna osoba i posljedica korištenja više od jednog jezika. Filipović ističe da su jezici u kontaktu oni koje naizmjenično upotrebljava isti govornik. Tu osobu naziva bilingvom, a tu pojavu bilingvizmom. Posljedicu te pojave da jedan govornik upotrebljava više jezika naziva interferencijom.

Element (riječ) X kako ga izgovaraju govornici jezika davatelja zovemo model, a posuđen element kako ga izgovaraju govornici jezika primatelja je replika.

Kad dva jezička sistema dođu u međusobni dodir, dolazi do preuzimanja riječi iz jednog jezika u drugi. Dva jezika koja sudjeluju u tom procesu nazivamo jezik davatelj i jezik primatelj.

Pri preuzimanju leksema iz jezika davatelja u jezik primatelja, u našem slučaju iz njemačkog jezika u bosanski jezik, događaju se određene promjene na različitim razinama. 


\section{Preuzimanje i adaptacija stranih riječi u drugi jezički sistem}

Prilikom preuzimanja stranih riječi u drugi jezik nastupa proces prilagođavanja ili adaptacije. Taj proces je neophodan s obzirom na to da su riječi često prilikom preuzimanja takvog fonološkog, ortografskog ili morfološkog oblika koji ne odgovara sistemu jezika primatelja.

Riječ se mijenja onoliko koliko je potrebno da bi se što bolje uklopila u novi sistem. Razine na kojima mogu, a ne moraju, nastupiti promjene su prema R. Filipoviću: fonološka, morfološka, semantička i leksička (Filipović 1986).

Adaptacija je dugotrajan proces, a do svog konačnog oblika prolazi primarne i sekundarne promjene, prema kojima se razlikuje primarna i sekundarna adaptacija.

Zadatak analize adaptacijskih procesa jeste opisati kroz koje je promjene prošla strana riječ u primarnoj fazi, tj. od trenutka posuđivanja do formiranja osnovnog, odnosno konačnog oblika - koja se u kontaktnoj lingvistici naziva replika - $\mathrm{i}$ koje se promjene javljaju na replici u sekundarnoj fazi, tj. od trenutka integracije u sistem jezika primatelja nadalje.

Različite jezičke razine zahtijevaju i različit pristup problemu. Svi teoretičari kontaktne lingvistike slažu se da posuđenica obavezno prvo prolazi kroz proces formiranja fonološkog oblika. Naime, fonološki sistemi dvaju jezika nikada se u potpunosti ne podudaraju, pa se fonološki elementi jezika davatelja mijenjaju domaćima koji su im najsličniji po artikulacijsko-akustičkim svojstvima, a problem fonološkog neuklapanja rješava se ispuštanjem ili umetanjem domaćih fonoloških elemenata.

Nakon fonološke adaptacije uvijek slijedi morfološka. Svaka strana riječ u trenutku prelaska u novi jezički sistem donosi sa sobom i morfološka obilježja vrste riječi kojoj pripada. Kako su morfološki sistemi različiti, posuđenica mora svoja morfološka obilježja uskladiti i prilagoditi pravilima jezika primatelja. Tu može, a ne mora, doći do preoblikovanja osnovnog oblika posuđenice.

Adaptacija germanizama na semantičkoj razini specifična je po tome što pripada području ljudskog uma, za razliku od fonološke i morfološke 
adaptacije koja se može karakterizirati kao mehaničko prilagođavanje (Talanga 2002).

\section{Obrada analize adaptacijskog procesa germanizama na semantičkoj razini}

U ovom radu akcent je stavljen na analizu procesa semantičke adaptacije germanizama u bosanski jezik, kako u primarnoj tako i u sekundarnoj fazi. Iz korpusa rada izdvojeni su germanizmi koji su frekventni iz područja domaćinstva (kuće i kućanstva, hrane, pića, odjeće, obuće, nakita i njege). To su: ancug, bademantil, beštek, bina, birtija, blajhanje, blenda, blic, brezle ili brizle, buhtle, brushalter, cajtung, celer, centrifuga, cimer, cvikere, deka, dihtung, dinstati, ementaler, escajg, fah, faltna, fasung, faširati, feler, fen, feniranje, fil, filc, filovati, flaša, flašica, flaširanje, flek, frišak, frištik, futer, futrola, gelender, gemišt, georgina, geršla, glancati, glanz, griz, haringa, haustor, heklanje, hozntreger, jakna, kanta, kifla, klofer, knedla, kofer, korpa, košpica, kragna, krigla, krofna, krompir, kuglof, ladica, ladičar, lajsna, lampa, mašna, mider, mileram, nitna, ofinger, pakung, pegla, pleh, princes-krofne, puter, rajf, rajsferšlus, rajslinga, rerna, ribati, roštilj, ruksak, saft, sala, senf, supa, šampita, šerpa, šlepa, šlic, šmekati, šminka, šnicla, šnita, šolja, špajz, špica, šporet, štala, štanglica, štapić, štekdoza, štepati, štikla, štirka, štruca, šunka, šupa, tapeta, tašna, tepih, tufna, uštopano, vaga, vekna, vindjakna, zihernadla...

Pri toj analizi držat ćemo se principa i metoda Rudolfa Filipovića, odnosno Hopeovog sistema podjele, koju je Filipović prihvatio u svojoj analizi, a potom modificirao. Filipović (1986: 161) u svojoj metodologiji ističe potrebu odvajanja adaptacijskih procesa na dvije faze i konstatira: "Primjenom primarne i sekundarne adaptacije na semantičkoj razini dobili smo novu podjelu koja zadovoljava potrebe naše analize semantičkih promjena odnosno promjena značenja kod posuđenica.”

Kao i na drugim razinama, Filipović koristi trodijelnu klasifikaciju. $\mathrm{Na}$ temelju poređenja značenja modela sa značenjem replike, Filipović promjene svrstava u tri kategorije: nulta semantička ekstenzija, suženje 
značenja i proširenje značenja. Ta podjela temelji se na razlikovanju primarne i sekundarne adaptacije.

Primarnoj adaptaciji pripadaju: nulta semantička ekstenzija (nema razlike u značenju između modela i replike), suženje značenja u broju (promjena od više značenja na jedno značenje) i suženje značenja u značenjskom polju (promjena od općeg značenja na posebno značenje).

Sekundarna adaptacija obuhvaća proširenje broja značenja i proširenje polja značenja. U sekundarnoj adaptaciji nastaju i promjene vezane uz metaforu, metonimiju, pejorizaciju i elipsu (Sočanac 1992).

\subsection{Nulta semantička ekstenzija}

Nulta semantička ekstenzija javlja se kad značenje njemačke posuđenice (replike) nakon ulaska u sistem bosanskog jezika ostaje nepromijenjeno i potpuno odgovara izvornom značenju njemačkog modela. Filipović promjene značenja te vrste naziva i prijenosom značenja. To se posebno odnosi na izraze čija su značenja tačno definirana. To su, naprimjer, stručni nazivi iz raznih područja, kao što su područja domaćinstva, gastronomije, tehnike, građevinarstva, sporta, poljoprivrede i drugih, kao i nazivi pripadnika različitih pokreta, učenja i pravaca ili imenice koje označavaju nositelja neke osobine, odnosno sastava. Preuzimanjem tih predmeta i njihovih izraza preuzima se ili zadržava njihovo značenje. Analizirajući germanizme iz korpusa odabranih termina iz oblasti domaćinstva, može se vidjeti da se u većini slučajeva radi o modelima koji imaju jedno ili manji broj značenja, a prenosi se samo jedno konkretno značenje. Rijetko se događa da se više značenja jedne riječi prenosi u jezik primatelja. Prema tome nulta semantička ekstenzija može se podijeliti na dvije skupine.

Prvu skupinu čine modeli s jednim preuzetim značenjem, kao što su to u našem korpusu:

birtija $<$ Wirtshaus $^{1}$ (gostionica), brizle $<$ Briesel (pečene janjeće ili teleće prsne žlijezde), buhtla $<$ Buchtel (domaći i pekarski kolač od dizanog

1 Rječnici koji su korišteni prilikom prevođenja germanizama na bosanski jezik su: Rječnik bosanskog jezika Ibrahima Čedića i saradnika, Rječnik bosanskog jezika 
tijesta), cajtung $<$ Zeitung (novine), dihtung $<$ Dichtung (npr. u pretis loncu), ementaler $<$ Emmentaler (tvrdi sir), feler $<$ Fehler (greška), fen $<$ Föhn (električni aparat za sušenje kose), flaša $<$ Flasche (boca), futer $<$ Futter (platno unutar odjeće), gelender $<$ Geländer (ograda), georgina $<$ Georgine (ukrasna biljka), geršl $<$ Gerste (jelo od ječma), glanc $<$ Glanz (sjaj), gris $<$ Grieß (krupno samljevena pšenica), haringa $<$ Hering (vrsta ribe), jakna $<$ Jacke (odjevni predmet dugih rukava), kanta $<$ Kanne (posuda), kifla $<$ Kipfel (pecivo u obliku polumjeseca), klofer $<$ Klopfer (naprava za isprašivanje tepiha), knedla $<$ Knödel (okruglo oblikovano i eventualno punjeno tijesto od krompira), kofer $<$ Koffer (predmet za prenošenje stvari), krigla < Krügel (čaša iz koje se pije pivo), kuglof $<$ Gugelhupf (vrsta kolača), pakung < Packung (vrsta kure za kosu), štikla $<$ Stöckel (potpetica).

Posebno bi trebalo istaknuti da su modeli našeg korpusa, koji također pripadaju toj grupi, često složenice sastavljene iz dvije riječi. Modeli složenica u našem korpusu pripadaju tipu Determinativkompositum, gdje svaka riječ unutar složenice ima svoje značenje i svoju funkciju u tvorbi složenice. Drugi dio složenice definira morfosintaksu i semantiku cijele riječi, a prvi dio ima funkciju da modificira semantiku drugog dijela složenice.

U modelima našeg korpusa vidljivo je da to nije bilo prepoznato prilikom preuzimanja njemačkih složenica u bosanski jezik te su složenice u cjelini prenesene i fungirale kao osnovni oblik, tako da su se adaptirale kao takve u fonetskoj i morfološkoj razini i potpuno integrirale $\mathrm{u}$ bosanski jezik.

Nekoliko modela složenica iz našeg korpusa s jednim preuzetim značenjem:

bademantil < Bademantel (ogrtač od frotira), bushalter $<$ Brusthalter (grudnjak), hozntreger < Hosenträger (traka preko ramena koja pridržava hlače), ruksak < Rucksack (naprtnjača), štekdoza < Steckdose (utičnica), vindjakna $<$ Windjacke (kaput od lakih i nepropusnih materijala), centrifuga $<$ Zentrifuge (stroj ili dio stroja koji radi djelovanjem centrifugalne sile), escajg < Esszeug (pribor za jelo), rajsferšlus (patentni

grupe autora Senahida Halilovića, Ibrahima Palića i Amele Šehović te Veliki rječnik stranih riječi Bratoljuba Klaića. 
zatvarač na odjeći), rajslinga (čavlić sa širokom glavom za pričvršćivanje nečega), zihernadla (igla s kopčom koja učvršćuje tkaninu).

Drugu skupinu čine modeli s dva i više preuzetih značenja:

blic $<$ Blitz (nešto na brzinu uraditi i dodatak fotoaparatu koji proizvodi svjetlost), farba < Farbe (boja i sredstvo za bojanje), pleh < Blech (lim i tepsija za pečenje), flek < Fleck (mrlja i potamnjeno mjesto), falta < Falte (kroj odjeće i sl. izveden nabor, udubljene linije na koži), šalter < Schalter (prozorčić u poslovnoj prostoriji, električni prekidač), fah < Fach (pretinac i specijalnost), cug $<$ Zug (vlak, šah potez, kombinirano sa $i z$ - iz cuga znači odjednom), špic < Spitze (vrh, vrhunac sezone ili sl., jezgro koštuničavog voća i vrsta psa).

\subsection{Suženje značenja}

Suženje značenja najčešća je pojava u semantičkoj adaptaciji stranih riječi. Analizirajući germanizme u bosanskom jeziku, možemo konstatirati da njemačke riječi imaju više nego jedno značenje i u procesu semantičke adaptacije u bosanski jezik većinom se zadržalo samo jedno značenje koje je bilo potrebno zbog imenovanja konkretnog pojma ili predmeta. Ono predstavlja specijalizaciju mnogih značenja modela na jedno specifično značenje. Ta se opća tendencija naziva suženje značenja.

Suženje značenja može se odnositi na suženje broja značenja, što je vrlo česta pojava. Neke posuđenice, pored tog suženja u broju značenja, pokazuju i dalje suženje u značenjskom polju. To je, dakle, dvostruko suženje: u broju značenja i u preuzetom polju značenja.

Korpus ovog istraživanja potvrđuje tendenciju suženja modela u broju i prenošenje jednog specifičnog značenja modela u sljedećim primjerima:

ancug < Anzug (odijelo, Duden 1a/6) ${ }^{2}$

Značenje riječi der Anzug u njemačkom jeziku: 1. odjevni predmet koji se sastoji od hlača i jakne (aus Hose und Jacke bestehendes

2 Prvi broj označava koje značenje je po redu evidentirano u rječniku Duden Universalwörterbuch, a drugi broj označava koliko značenja ukupno navodi rječnik pod natuknicom tog modela. Taj podatak je relevantan da bi se uočilo suženje u broju. Sva značenja u njemačkom jeziku su preuzeta iz navedenog rječnika, a prijevodi su autoricini. 
Kleidungsstück) 2. sposobnost ubrzavanja (Beschleunigungsvermögen) 3. približavati se (Redewendung: im Anzug sein = sich nähern...) 4. oblačenje ili privlačenje (das Anziehen) 5. pokrivač (Bettbezug, Überzug) 6. prijedlog u Saboru (Antrag im Parlament).

beštek $<$ Besteck (pribor za jelo, Duden 1/3)

Značenje riječi das Besteck u njemačkom jeziku: 1. pribor za jelo (Essbesteck) 2. skup instrumenata sastavljenih za određenu medicinsku svrhu (für einen bestimmten medizinischen Zweck zusammengestellter Satz von Instrumenten) 3. položaj broda na moru (Ortsbestimmung eines Schiffes auf See).

deka $<$ Decke (pokrivač, Duden, 2/8)

Značenje riječi die Decke u njemačkom jeziku: 1. okrugli ili četvrtasti stolnjak ili prekrivač (rundes oder eckiges Stoffstück aus Leinen, Halbleinen, Baumwolle o. Ä. zum Bedecken besonders eines Tisches) 2. pokrivač od toplog tekstilnog materijala (aus wärmendem textilem Material hergestellter Gegenstand zum Zudecken) 3. plafon, vrh sobe (oberer Abschluss eines Raumes).

fasung $<$ Fassung (sljedovanje hrane, Duden 6b/6)

Značenje riječi die Fassung u njemačkom jeziku: 1a. rub - često umjetnički urađen - u svrhu pričvršćivanja predmeta (der Befestigung eines Gegenstands in etwas dienende, oft kunstvoll ausgearbeitete Umrandung, Einfassung) 1b. obruč koji služi za hvatanje i prikupljanje vode npr. na bunaru (dem Auffangen, Sammeln von Wasser (besonders eines Brunnens) dienende [ausgemauerte] Umrandung) 1c. držač za uvrtanje ili stezanje (Haltevorrichtung zum Festschrauben oder Festklemmen) 2. jezički oblik, oblik; formulacija (sprachliche Form, Ausformung; Formulierung) 3. slikanje u boji ili pozlaćivanje skulpture od drveta ili kamena 4. samokontrola (Selbstbeherrschung) 5. hvatanje (das Ergreifen) 6. velika količina (Ladung - größere Menge).

fil < Füllung (nadjev, smjesa Duden 2a/3)

Značenje riječi die Füllung u njemačkom jeziku: 1. punjenje (das Füllen) 2a. smjesa koja se dodaje određenom jelu zbog obogaćivanja (Masse, die zur Anreicherung in bestimmte Speisen hineingefüllt wird) 2b. blomba (Masse, die den Hohlraum in einem Zahn nach dem Ausbohren ausfüllt) 2c. materijal u madracima, jorganima, jastucima (Material in Matratzen, Federbetten, Kissen) 3. panel za vrata (Türfüllung). 
filc $<$ Filz (vrsta netkanog tekstila, Duden 1/8)

Značenje riječi der Filz u njemačkom jeziku: 1. gusti materijal napravljen presovanjem uglavnom od ovčije vune i druge životinjske dlake (durch Pressen vorwiegend aus Schafwolle und anderen Tierhaaren hergestelltes dichtes Material) 2. dlačica (Fussel) 3. skraćenica za Filzhut (Kurzform für Filzhut) 4. skraćenica za Bierfilz (Kurzform für Bierfilz) 5. močvara (Moor) 6. škrta ili neotesana osoba (geiziger oder ungehobelter Mensch) 7. neotopljena svinjska mast (ungeschmolzenes Bauchfett des Schweines).

grunt $<$ Grund (zemljišna parcela, Duden 1c/5)

Značenje riječi der Grund u njemačkom jeziku: 1a. tlo, Zemljina površina (Erdoberfläche, Boden) 1b. nekretnina, imovina (Grundbesitz; Grundstück) 2. mala dolina (kleines Tal) 3a. dno u vodama (Boden eines Gewässers) 3b. najniža površina, dno posude (unterste Fläche, Boden eines Gefäßes) 4. područje koje čini pozadinu ili dno za nešto (Fläche, die den Hintergrund, den Untergrund für etwas bildet) 5. činjenica, motiv, razlog (Umstand, Tatbestand, Motiv, Beweggrund)

kragna $<$ Kragen (dio košulje, Duden 1a/4)

Značenje riječi der Kragen u njemačkom jeziku: 1a. dio odjeće koji djelomično ili potpuno okružuje vrat (den Hals teilweise oder ganz umschließender Teil der Kleidung) 1b. odvojen, nepričvršćena kragna na odjeći (einzelner, nicht fest an ein Kleidungsstück genähter Kragen) 2a. vrat - obično od peradi (Hals - meist von Geflügel) 2b. grlo boce (Hals einer Flasche) 3. pruge koje vire na ostatku krzna ili perja oko vrata životinja (gegen das übrige Fell oder Gefieder abstechender Streifen um den, am Hals von Tieren) 4. fraza jemandem platzt der Krage sa značenjem: pući od bijesa; fraza jemandem / jemanden den Kragen kosten sa značenjem: košta ga glave; fraza jemandem den Kragen [her]umdrehen sa značenjem: ubiti nekoga; fraza jemanden am Kragen kriegen / packen; jemanden beim Kragen packen / nehmen sa značenjem: uhvatiti nekoga i suočiti se s njim; fraza es geht jemandem an den Kragen sa značenjem: smatrati nekoga odgovornim i zbog toga ga kazniti; fraza: jemandem an den Kragen wollen sa značenjem: okriviti nekoga za odgovornost, nanijeti mu štetu ili prebiti ga.

rerna $<$ Röhre (dio štednjaka u kojem se peku namirnice, Duden 3/6) Značenje riječi die Röhre u njemačkom jeziku: 1. dugo cilindrično šuplje tijelo [sa manjim promjerom], koje se uglavnom koristi za transport 
plinova ili tekućina (langer zylindrischer Hohlkörper [mit geringerem Durchmesser], der vor allem dazu dient, Gase oder Flüssigkeiten weiterzuleiten) 2. mala cjevčasta posuda (kleiner röhrenförmiger Behälter) 3. cijev za pečenje i prženje (Back-, Bratröhre) 4a. elektronske cijevi, posebno radijske ili televizijske cijevi (Elektronenröhre, besonders Radiooder Fernsehröhre) 4b. fluorescentna cijev, neonska cijev (Leucht[stoff] röhre, Neonröhre) 5. ekran, televizor (Bildschirm, Fernsehgerät) 6. podzemni prolaz građevine cjevastog oblika (röhrenförmiger unterirdischer Gang eines Baus).

šlic $<$ Schlitz (prorez, Duden 2/4)

Značenje riječi der Schlitz u njemačkom jeziku: 1. izduženi, uski otvor u nečemu (längliche, schmale Öffnung in etwas) 2. skraćenica za riječ Hosenschlitz sa značenjem šlic na hlačama (Kurzform für Hosenschlitz) 3. otvoren, uzak, izduženi rez na odjeći (offener, schmaler, länglicher Einschnitt in einem Kleidungsstück) 4. stidno mjesto (Schamspalte).

štos $<$ Stoss (hrpa, Duden 5/6)

Značenje riječi der Stoss u njemačkom jeziku: 1a. brzi pokret koji nekoga ili nešto udari snažnim udarcem (schnelle Bewegung, die in heftigem Anprall auf jemanden, etwas trifft) 1b. udaranje kugle (das Stoßen der Kugel) 2. udarac, ubod oružjem (Schlag, Stich mit einer Waffe) 3. trzaji prilikom plivanja, veslanja (ruckhaft ausgeführte Bewegung beim Schwimmen, Rudern) 4a. trzavi, ritmični pokreti (stoßartige, rhythmische Bewegung) 4b. skraćenica riječi Erdstoß sa značenjem zemljotres (Kurzform für Erdstoß) 5. naslagana gomila, stog, plast (aufgeschichtete Menge; Stapel) 6. jedinstvena ofenzivna borbena akcija (einzelne offensive Kampfhandlung).

Suženje značenja u značenjskom polju javlja se vrlo rijetko. Zapravo, teško je tačno utvrditi koliko se smanjuje, odnosno sužava značenjsko polje. To su primjeri koji su već prošli suženje u broju i pokazuju i dalje suženje u značenjskom polju. Primjeri za sužavanje u značenjskom polju u našem korpusu su modeli šolja, brile, gemišst.

Naprimjer replika šolja < Schale u njemačkom jeziku ima, prema Dudenu, jedanaest značenja. Između ostalog označava zdjelu oblika polukugle. U tom smislu, ta se riječ ne koristi u bosanskom jeziku, već je došlo do suženja polja značenja i koristi se u smislu "manja posuda s ručkom sa strane iz koje se pije kafa ili čaj”. Da bi se ta umanjenost 
potvrdila, koristi se često deminutiv te riječi šoljica. U njemačkom jeziku s tim značenjem riječ se ne koristi.

\subsection{Proširenje značenja}

U sekundarnoj fazi integrirana strana riječ može zadržati svoje značenje u jeziku primatelja, a može dobiti i nova značenja koja u jezi$\mathrm{ku}$ davatelja ne postoje, te se radi o proširenju značenja. U ovoj fazi posuđenica gubi na preciznosti, a dobiva na širini značenja (Filipović 1986: 169-170). Za proširenje značenja potrebna su dva osnovna uvjeta: potpuna fonološka, morfološka i semantička integracija posuđenice $\mathrm{u}$ sistem jezika primatelja i njezina slobodna upotreba u sklopu tog jezika. Prema tome, proširenje značenja pojava je isključivo sekundarne adaptacije. Sekundarna semantička adaptacija obuhvata proširenje broja značenja i proširenje polja značenja. Filipović (1986: 179), polazeći od Hopeove definicije, navodi četiri osnovna tipa promjena zavisno od načina promjene značenja. Tako postoje: a) metafora (sličnost po značenju), b) metonimija (povezanost po značenju), c) pučka etimologija (sličnost po obliku), d) elipsa (povezanost po obliku).

\subsubsection{Metafora}

Za prikaz utjecaja metafore može nam poslužiti primjer germanizma šlauf < Schlauch. U primarnoj fazi adaptacije prenesena su dva značenja iz njemačkog jezika: "crijevo" i "pojas za plivanje”. Drugo značenje je poslužilo kao podloga za proširivanje značenja, odnosno stvaranje novog metaforičkog značenja riječi šlauf u smislu "naslage sala oko pojasa”. U bosanskom jeziku posuđenica šlauf koristi se sa sva tri različita značenja. Prva dva značenja prenesena su u primarnoj adaptaciji i riječi s tim prvobitnim značenjima postale su frekventne u bosanskom jezi$\mathrm{ku}$, a svojom produktivnošću u bosanskom jezičkom sistemu stvorile su novo metaforičko značenje.

Pored mogućnosti pojave metaforičkog značenja, riječ može ostati neutralnog značenja ili dobiti pejorativnu nijansu. Većinom uz upotrebu metaforike slijedi i pejorizacija. U našem korpusu u većini se slučajeva 
germanizam šlauf u smislu "naslage sala oko pojasa" koristi u pejorativnom značenju.

Ostali primjeri koji imaju, pored izvornih značenja, novotvorena metaforička značenja s nijansom pejorizacije su npr.: fasovati (primiti nešto, biti kažnjen), peglanje (gnjaviti, dosađivati), šerafiti ili ošerafiti (udariti nekoga ili poniziti).

Primjer posuđenica koje su dobile metaforičko značenje, a nemaju nijansu pejorizacije je npr. riječ blenda s neutralnim značenjem "zaslon ili pregrada”.

\subsubsection{Metonimija}

Posuđenica čije se značenje proširilo, između ostalog, i pod utjecajem faktora metonimije jeste, naprimjer, germanizam štapići (slane grickalice duguljastog oblika).

Njemačka posuđenica štap < Stab preuzeta je u bosanski jezik sa značenjem "klip" ili "pomagalo za rad ili hodanje". U tom obliku i s tim značenjima riječ štap postaje aktivna i podložna promjenama na različitim razinama kao i bilo koja domaća riječ. Dodavanjem sufiksa -ić, koji tvori deminutiv u bosanskom jeziku, formirala se nova riječ štapić (imenica u jednini). Dodavanjem sufiksa - $i$ kojim se tvori množina štapići u smislu "grickalica duguljastog oblika malih štapova". Termin štapići koristi se u različitim složenicama sa značenjem "oblika malog štapa”, kao npr. riblji štapići, čarobni štapić, dirigentski štapić...

\subsubsection{Pučka etimologija}

Pučka etimologija je jezički faktor čije je djelovanje najčešće prisutno u procesu posuđivanja riječi. Neintegrirane ili nepotpuno integrirane riječi, ili pak dijelovi riječi, naslanjaju se na domaće riječi na formalno-jezičkoj i na semantičkoj razini. U toku adaptacije riječi se glasovno i sadržajno približe nekoj domaćoj riječi.

Posuđenica lumpati (lumpovati) potječe od njemačke posuđenice lump > Lump koja se potpuno adaptirala značenjem "lutalica". U sekundarnoj 
adaptaciji od imenice lump tvoreni glagol lumpati mijenja značenje, naslanjajući se snagom pučke etimologije na značenje bosanskog glagola lupati. Značenje glagola lumpati ne preuzima značenje lutati (analogno, ako lump znači "lutalica", lumpati bi trebalo značiti "lutati"), kao što bi se moglo očekivati, nego se mijenja značenje. Lumpati se povezuje sa sličnom bosanskom riječi lupati, tako da dolazi do miješanja značenja, te riječ lumpati preuzima značenje bosanskog glagola lupati i zadržava značenja lekseme lutati. Dakle, pored integrirane posuđenice lump sa značenjem "lutalica", došlo je do novotvorene riječi lumpati i lumperaj s novim značenjem "lutanje i lupanje uz konzumiranje alkohola".

\subsubsection{Elipsa}

Kod elipse dolazi do izostavljanja elemenata, a kad je riječ o germanizmima u našem korpusu, to je uglavnom slučaj kod složenica u kojima se preuzima cijelo značenje, ali se već u primarnoj fazi tokom formiranja replike gubi jedan dio. U sljedećim germanizmima izostavljen je prvi dio složenice: rerna < Backröhre, štok < Türstock, treger $<$ Gepäckträger.

Ostali primjeri pokazuju izostavljanje drugog dijela složenice. To su germanizmi:

cimer $<$ Zimmerkamerad, lug $>$ Laugenbad, mider $<$ Miederhöschen, pegla $<$ Bügeleisen, šlag $<$ Schlagsahne, štikla $<$ Stöckelschuhe, štrample $<$ Strampelhöschen, šverc $<$ Schwarzhandel, ziherica $<$ Sicherheitsnadel.

\section{Zaključak}

Klasificirajući germanizme s obzirom na pripadajuća tematska područja, došli smo do rezultata da su germanizmi najzastupljeniji i najfrekventniji u području domaćinstva, te je formiran korpus od 123 germanizma koji su podvrgnuti analizi adaptacijskih procesa na semantičkoj razini.

Rezultati istraživanja analiziranih germanizama pokazuju koliko je adaptacija germanizama u ovom polju složenija u odnosu na fonološku 
i morfološku adaptaciju, s obzirom na to da se ne radi o mehaničkom prilagođavanju, nego da ovo područje pripada ljudskoj jezičkoj kreativnosti.

$\mathrm{Na}$ temelju analize adaptacijskih promjena u primarnoj fazi možemo konstatirati da su analizirani germanizmi uglavnom preuzeti u bosanski jezik sa svojim konkretnim značenjima kao npr. birtija, brezla, celer, gris itd. U cijelom analiziranom korpusu došlo je do suženja broja značenja u jedanaest slučajeva, a u tri primjera primijećeno je dalje suženje u značenjskom polju.

Za razliku od primarne adaptacije kod koje je jasno određen početak i kraj, sekundarna adaptacija jasno je određena što se tiče početka, tj. formiranja primarne replike na osnovu primarnog modela. Završetak se ne može odrediti, jer se replika može mijenjati u toku razvoja bosanskog jezika. Te promjene se ne povezuju više s njemačkim jezikom jer su uvijek vezane samo za bosanski jezički sistem i njegova pravila. To dokazuju primjeri germanizama kod kojih je u fazi sekundarne adaptacije došlo do proširenja značenja upotrebom metafore, metonimije, pejorizacije, pučke etimologije i elipse.

Od ukupno devetnaest germanizama koji su doživjeli promjenu značenja u sekundarnoj fazi, zabilježeno je pet primjera kod kojih je promjena nastala metaforom. U korpusu je zabilježen i po jedan germanizam čije se značenje proširilo pod utjecajem metonimije i pučke etimologije.

Na kraju možemo zaključiti da svaki germanizam u sekundarnoj adaptaciji postaje model koji može poslužiti za tvorbu kako novih leksema tako i novih značenja. Prema tome, proces sekundarne adaptacije ostaje otvoren sve dok se germanizam upotrebljava u bosanskom jeziku.

\section{Literatura}

Čedić, Ibrahim et al. (2007): Rječnik bosanskog jezika, Institut za jezik, Sarajevo.

Burnić, Hatidže (2011): Germanizmi u štampi Bosanske krajine, magistarska teza, Mostar. 
Duden (2001): Herkunftslwörterbuch, Dudenverlag, Mannheim.

Duden (2003): Universalwörterbuch, Dudenverlag, Mannheim.

Filipović, Rudolf (1986): Teorija jezika u kontaktu, JAZU - Školska knjiga, Zagreb.

Halilović, Senahid; Palić, Ismail; Šehović, Amela (2010): Rječnik bosanskoga jezika, Filozofski fakultet, Sarajevo.

Klaić, Bratoljub (1974): Veliki rječnik stranih riječi, Zora, Zagreb.

Sočanac, Lelija (1992): "Morfološka adaptacija anglicizama u talijanskom jeziku”, EUR - Eko usmjereni razvoj 20/21, 413-424.

Talanga, Tomislav (2002): "Pučka etimologija među nekim njemačkim posuđenicama”, Jezikoslovlje 3 (1-2), Osijek, 193-216. 


\title{
Semantical adaptation of frequency germanisms in the field of household
}

\begin{abstract}
The task of the analysis of adaptation processes is to describe which changes the foreign word has undergone in the primary phase, ie from the moment of borrowing to the formation of the basic form - which in contact linguistics is called replica - and which changes occur in the replica in the secondary phase, ie from the moment of integration in the language system of the recipient further. This paper analyzes the semantic adaptation of frequency Germanisms in the Bosnian language system and focuses on the conceptual field of "household". The main goal is to determine the semantic changes that words taken from the German language undergo during the download and adaptation to the Bosnian language system. During the analysis, the contact linguistic methodology of Rudolf Filipović was used, in which the adaptation processes are divided into primary and secondary phases of adaptation. The comparative method compared the meanings of German models with the meanings of Bosnian replicas, and the changes were classified into three categories: zero semantic extension, narrowing of meaning and broadening of meaning.

Based on the analysis of adaptive changes in the primary phase, it was determined that Germanisms were mostly taken over into the Bosnian language with their specific meanings, but the category of narrowing in the field of meaning was also noted. Unlike the primary adaptation, the secondary adaptation includes changes that occur on the formed replica. These changes are no longer associated with the German language because they are always related only with the Bosnian language system and its rules. This is evidenced by the examples of Germanisms in which in the phase of secondary adaptation there was an expansion of meaning through the use of metaphor, metonymy, pejorization, folk etymology and ellipse.
\end{abstract}

Key words: germanisms, semantic adaptation, primary and secondary phase

Izjava autora o nepostojanju sukoba interesa i poštivanju općih etičkih kodeksa:

Autor potvrđuje da ne postoji nikakav stvarni ili mogući sukob interesa vezan za ovaj tekst te da je tekst napisan u skladu s etičkim kodeksima prema preporukama COPE (Committee of Publishing Ethics). 